\title{
Commentary
}

\section{Low Dose Radiation and No Health Risk in Fukushima in Contrast to Chernobyl}

\author{
Jun Takada ${ }^{1}$ \\ Division of Radiation Protection, Graduate School of Medicine, Sapporo Medical University, Hokkaido, Japan
}

Received February 1, 2013; Revised June 19, 2013; Accepted June 19, 2013

J-STAGE Advance published date: July 1, 2013

Radiation hygiene survey has been conducted in the East Japan earthquake area, about Fukushima Dai-Ichi nuclear power station disaster caused by tsunami on March 11, 2011. Our surveys revealed that a public annual dose was $10 \mathrm{mSv}$ following the disaster and health hazards should not be concluded by the methods of in situ dose evaluation. This study has been focused on internal dosimetries of iodine-131 in thyroid and of cesium-134, 137 in whole body. Further, we continuously have been studying radiation hygiene on cattle livestock in Namie town located within $20 \mathrm{~km}$ zone around the Fukushima Daiichi nuclear power station, and found no problem for the recovery.

Key words: Fukushima, radiation hygiene, individual dosimetry

\section{Investigations of Radiation Hygiene in Fukushima}

Ensuing residents from reactor accidents caused by tsunami at Fukushima Dai-Ichi Nuclear Power Plant in March 2011, the author has freely conducted, as a scientist in the discipline of radiological protection science, on-site radiological hygiene surveys in an autonomous format apart from any organization. The survey started from Sapporo by land on April 6, 2011 and covered areas in Aomori, Sendai, Fukushima Prefectures and Tokyo until April 10, 2011, checking the radiation hygiene conditions at various sites using a mobile laboratory (Fig. 1) $(1,2)$. In the beginning, the most feared short-term nuclear hazard (risk factor) was considered to be thyroid doses from radioactive iodine. Tests were completed for 66 individuals including 40 evacuees from Namie-machi which is located within $20 \mathrm{~km}$ from Fukushima Dai-Ichi Nuclear Power Plant.

Subsequently, from April 2011 to March 2012, assessments of actual external radiation doses with individual dosimeters and surveys of internal radiation doses according to whole body counters on-site for internal cesium were performed for 93 individuals, from newborns to adults, in the communities of Minami Soma, Koriyama, Iwaki, Fukushima city, Aizu and Nihon-

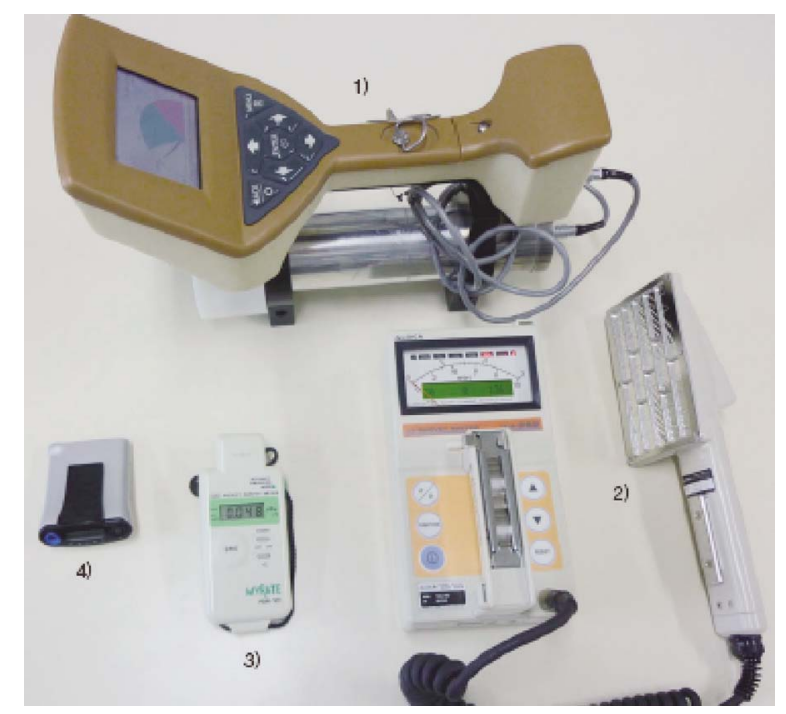

Fig. 1. (Color online) Portable laboratory. 1) gamma ray spectrometer 2inc NaI detector Modl702 Ludlum Measurements Instruments Inc., 2) alpha and beta counter, TSC-362 Aloka, 3) dose rate meter, PDR-101, 4) dosimeter and dose rate meter, RAD-60S RADOS Technology.

matsu, as requested by residents (3-5).

The methodology used was a systematic and consistent assessment based on both the external and internal exposures to radiation measured by a mobile laboratory, and was developed by myself for joint investigations with Russian scientists in the past $(6,7)$. This methodology allows health impacts by nuclear hazards to be evaluated in a rapid and quantitative manner. The thyroid dose-measurement method that was developed a decade ago was also applied for the first time. A portable gamma ray spectrometer, made in the United States for counter-nuclear terrorism purposes and procured just three months before the earthquake, was also mobi-

${ }^{1}$ Correspondence to: Jun Takada, S-1, W-17, Sapporo 060-8556, Japan. Tel: +81-11-611-2111, Fax: +81-11-644-2001, E-mail: juntakada@sapmed.ac.jp

doi: org/10.3123/jemsge.2013.005 


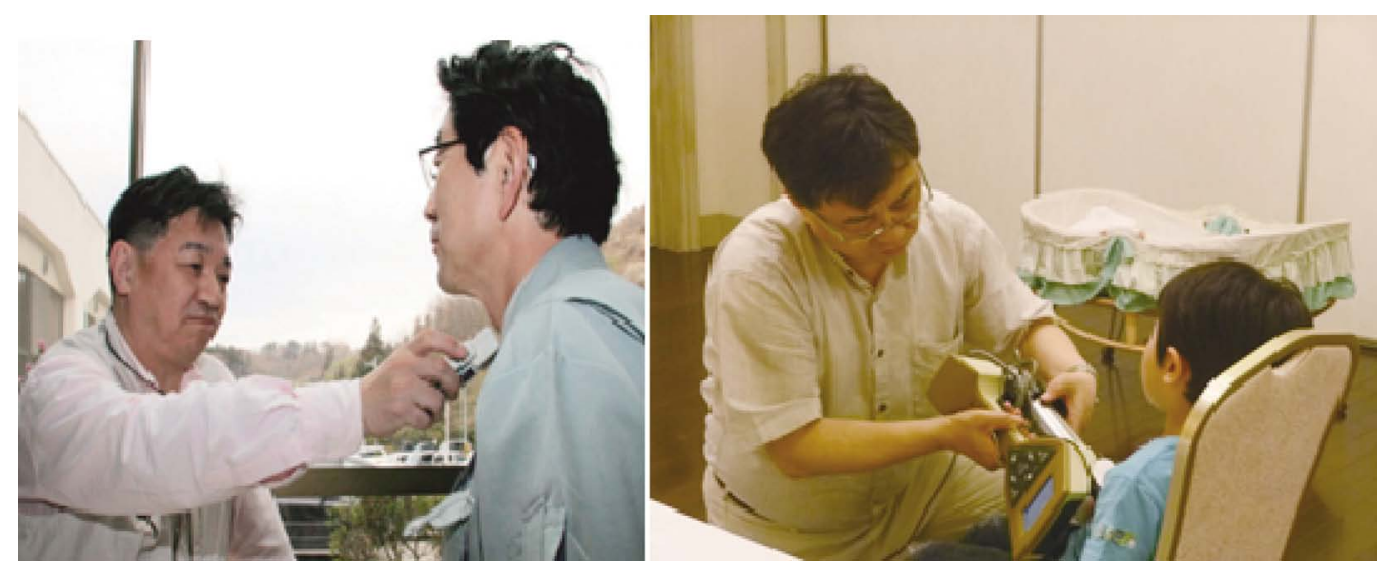

Fig. 2. (Color online) Measurements of internal exposures in Fukushima prefecture. Left) detection of I-131 activity, Right) whole body counting of radioactive cesium.

lized.

\section{Low Dose Radiation in Fukushima Population}

The results of thyroid dosimetry (Fig. 2, left) for 66 individuals confirmed low doses of $8 \mathrm{mSv}$ or less, approximately less than one thousandth of the Chernobyl accident's maximum thyroid radiation dose of $50 \mathrm{~Sv}$ $(1,2)$.

As for 93 individuals for total body cesium radioactivity (Fig. 2, right), 83\% were below the detection limit [10 Becquerels (Bq) or less per $\mathrm{kg}$ body weight] (5). For the remaining $17 \%$, the individual with the largest reading was $165 \mathrm{~Bq}$ per $\mathrm{kg}$-an estimated annual dose of 0.4 $\mathrm{mSv}$, which is completely within the range of safety, because the annual average dose for internal exposure globally from natural radiation is $1.3 \mathrm{mSv}$.

On April, June, and August in 2012, I conducted investigations of exposure to radiation in Fukushima Prefecture for two nights and three days on each occasion with a personal dosimeter on my chest $(3,8)$. I entered into the $20-\mathrm{km}$ zone for two days in April, as close as the property line of Fukushima Dai-Ichi Nuclear Power plant, and measured a total dose of $0.10 \mathrm{mSv}$. For my investigations in June, I travelled to Fukushima, Iitate-mura, Minami Soma, and Iwaki, and sustained a total dose of $0.01 \mathrm{mSv}$. My investigation in August of Shirakawa, Aizu, and Fukushima resulted in a total dose of $0.006 \mathrm{mSv}$. After the first month, radioactivity fell to a level of $1 / 4$ or less and continues to attenuate $(1,2)$.

Assessment results revealed external doses of prefectural residents to be $10 \mathrm{mSv} / \mathrm{y}$ or less, a large majority to be $5 \mathrm{mSv} / \mathrm{y}$ or less, and as for internal cesium exposure, all 98 tested individuals had ultra-low doses of less than $1 \mathrm{mSv} / \mathrm{y}$. Compared to the Chernobyl accident that found max. $750 \mathrm{mSv}$ cumulative external dose, and $100 \mathrm{mSv} /$ day for evacuees within $30 \mathrm{~km}$, Fukushima recorded levels of merely one hundredth.

I have an experience of investigations on radiation

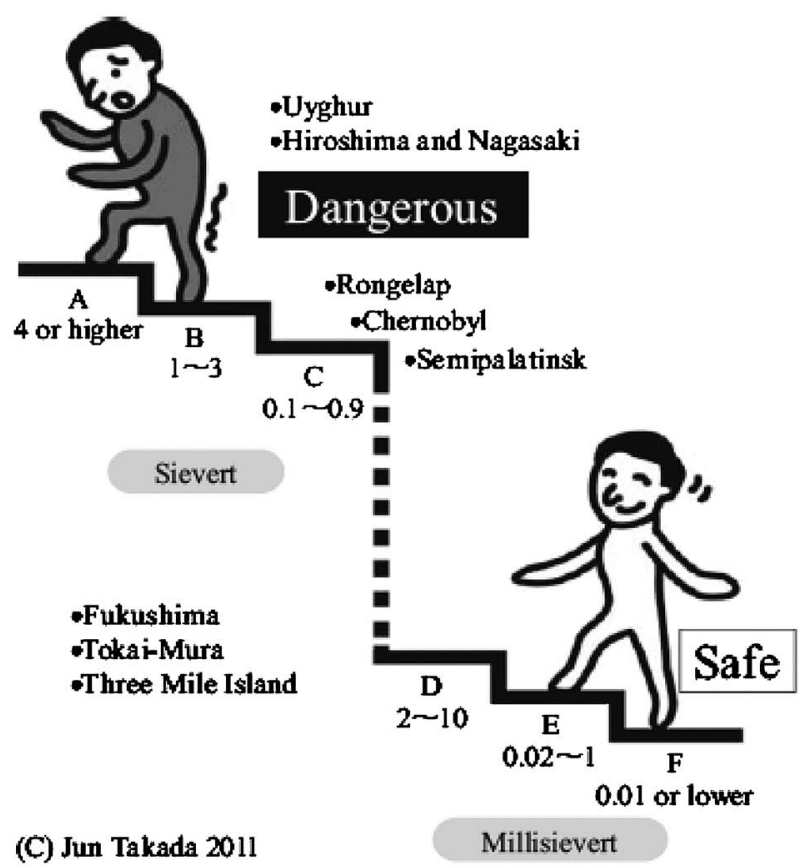

Fig. 3. Comparison of dose level among worldwide nuclear disasters (2).

hygiene in the most contaminated settlement of Zaborie in Russia 1997 (6). The evaluation of doses was 3.6 $\mathrm{mSv} / \mathrm{y}$ for Cs-137 internal exposure and $13 \mathrm{mSv} / \mathrm{y}$ for external exposure. This showed us that internal dose in the first and second year of disaster of Fukushima is one order magnitude less than that in Zaborie where contamination occurred with Chernobyl accident in 1986 (Fig. 3).

There are three reasons for much lower internal dose in Fukushima than that in Chernobyl, 1) low Cs contamination, 2) government control on foods markets by the tentative limit of radioactivity based on nuclear safety committee and 3) Japanese food consumer style 
based on wide variety of food origin from not only domestic but also international products. Therefore, it is not only non-scientific but also destructive to the local agricultures that the new limitation by the government for radioactivity for food is lower than natural radioactivity.

\section{Namie-machi Repatriation Possible}

Actual doses can be learned from an on-site survey of 3 days and 2 nights. The figures announced by the central Japanese government, however, are radiation doses calculated from air dose rates from fields without investigating actual doses of inhabitants, and are problematically in excess by a factor 4 to 5 of these actual doses. Families wishing to go home cannot do so under these assessments. Measurement results like a report card of a terrible underachiever are determining policy. Any student in my course would be getting failing marks. The individual dosimeter worn on my chest for 3 days and 2 nights during the March, 2012 survey at Suenomori in Namie-machi registered cumulative external dose of $0.074 \mathrm{mSv}$ or dose rate of $0.051 \mathrm{mSv}$ per 24 h. When the decay of the physical half-life ( 2 years and 30 years) for each of the cesium isotopes is considered, the cumulative dose for the entire calendar year 2012 living continuously and exclusively at Suenomori Ranch was estimated as $17 \mathrm{mSv} / \mathrm{y}$. Cesium tests for people commuting from temporary housing in Nihonmatsu five days a week to Namie-machi to care for cattle provided a result of $0.3 \mathrm{mSv}$ for internal exposure, an extremely low dose (Fig. 4).

The total dose for internal and external exposure that would permit repatriation is $20 \mathrm{mSv} / \mathrm{y}$ max., according to the government. Decontamination of topsoil for the home and ranchland under the nation's responsibility would bring levels below $5 \mathrm{mSv} / \mathrm{y}$, immediately. Current policy has no scientific grounds (9). The government is simply neglecting the $20 \mathrm{~km}$ radius. This neglect is the same for Iitate Village.

I surveyed the radioactivity when I was in Suenomori

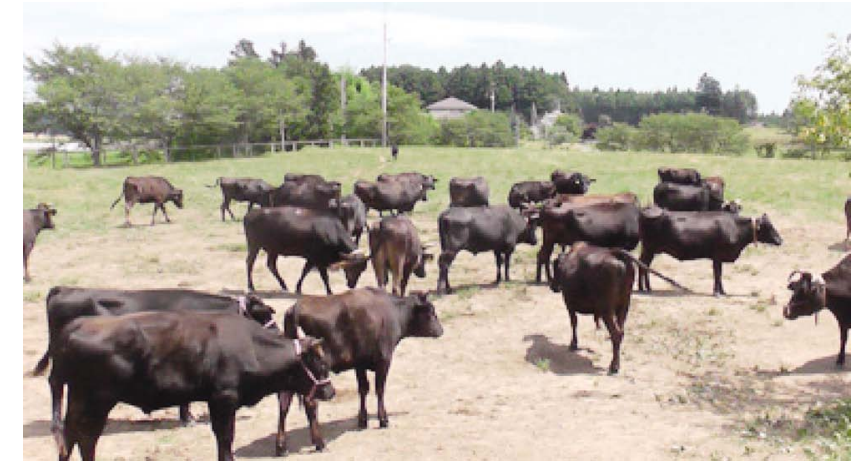

Fig. 4. (Color online) Healthy cattle of Yamamoto Ranch in Suenomori, Namie-machi, August 2012. of Namie-machi, and calculated exposure dose to be 96 $\mathrm{mSv} / \mathrm{y}$ by the non-scientific method of multiplying the government's outdoor figure by total hours in a year. The value obtained by the government's method leads to the wrongful judgment that repatriation is impossible, although people can return safely. The government is ignoring an application of my method, and creating a terrible situation of not fulfilling responsibility for a recovery. Despite this, the residents are advancing the project with me to voluntarily protect their homeland.

I hope the readers of my article can understand the significance of this testing research and recovery measures. We need to deploy science in order to clarify matters within the $20 \mathrm{~km}$ radius, criticize the misjudgment on the part of the government, and push for corrections to the erroneous policy (5).

\section{Change the Wrong Measurements-Determine Policy of the Former Government of Democratic Party}

The national government should take responsibility for the accident, and efficiently decontaminate the really contaminated area within the $20-\mathrm{km}$ zone of Fukushima Dai-Ichi Nuclear Power Plant. In Namie-machi in particular, farmers have been taking care of cattle, which remain alive. Beginning in February, 2012, the author has conducted scientific surveys with the cattle farmers who are enthusiastic about a recovery. I believe a model project should be launched with several of these cattle farms (10). Restoration of the entire $20-\mathrm{km}$ zone will require large-scale decontamination of farmland. But instead of tracts of unpopulated mountainous forest, farmland should be assigned a priority.

My proposed solution combines two ideas: the construction of a levee against large-scale tsunami in the future and the decontamination operation within the

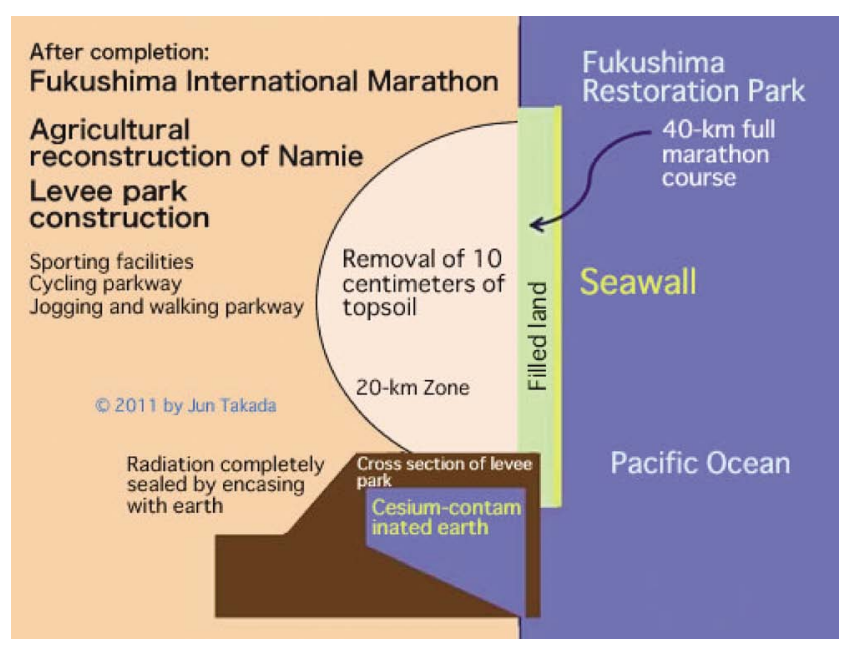

Fig. 5 (Color online) Reconstruction that combines decontamination and levee construction within the $20-\mathrm{km}$ zone. 
$20-\mathrm{km}$ zone. The coast for a stretch of approximately 40 $\mathrm{km}$ can be filled, together with the rubble collected from within the zone, to create a levee park.

This was proposed last October in a study group meeting at on-site Iwaki when I was invited as a speaker, and gained support from many participants. Later, I have also proposed this to the Prime Minister of Japan and His Cabinet.

After the Great Kanto Earthquake of 1923, the City of Yokohama filled its oceanfront with rubble from 60,000 houses and built Yamashita Park. For the 21st century, Japan should be able to build a $40-\mathrm{km}$ levee park in Fukushima. After completion, an international marathon can be held to commemorate the recovery of Fukushima. It is time to show the scientific prowess and strong will of Japan to the world (Fig. 5).

Conflict of interest: The author declares that there are no conflicts of interest.

\section{References}

1 Takada J. Fukushima Myth and Reality. Tokyo: Iryokagakusha; 2011. p. 1-72. (Japanese)

2 Takada J. Fukushima Myth and Reality. Tokyo: Iryokagakusha; 2012. p. 1-59.

3 Takada J. The path to reconstruction in Fukushima, as seen through fieldwork in the Eastern Japan. APA Group. (http://www.apa.co.jp/book_ronbun/vol4/2011 einglish.html). 2011.

4 Takada J. Fukushima: Neither Chernobyl, Nor Hiroshima. Global Energy Policy Research, (http://www.gepr. org/en/contents/20120220-01/). 2012.

5 Takada J. Current state of radiation doses in Fukushima Prefecture: No health risk, calling for institution of scientific measurements and correction to wrong policy. Global Energy Policy Research, (http://www.gepr.org/ en/contents/20121001-01/). 2012.

6 Takada J. Nuclear hazards in the world. Tokyo: Kodansha and Springer; 2005. p. 1-134.

7 Takada J. Developments of in-situ evaluation of internal dose. Research report, the Japan Society for the Promotion of Science under Grant no. 10558088, awarded to J. Takada, 2001. (Japanese)

8 Radiation Protection Information Center, Fukushima Support Page. (Japanese) (http://rpic.jp/hygiene/ fukushima/). 2013.

9 Takada J. Ill Intent and Non Science of Government's Estimation: "Extreme Non-Science" Establishes “'Repatriation Difficulty Zone'. Gekiron 6, Okura Publishing, 2012. p. 107-113. (Japanese)

10 Takada J. On-site survey with Fukushima livestock farmers reveal non science of Noda Government's "No Trespassing Zone'. Gekiron 4, Okura Publishing, 2012. p. 133-141. (Japanese) 